\title{
Adhesion Behavior of Escherichia coli Strains on Glass: Role of Cell Surface Qualitative and Quantitative Hydrophobicity in Their Attachment Ability
}

\author{
Kaoutar Elfazazi (DD, ${ }^{1,2}$ Hafida Zahir, ${ }^{1}$ Safae Tankiouine, ${ }^{1}$ Btissam Mayoussi, ${ }^{1}$ \\ Chorouk Zanane, ${ }^{1}$ Souad Lekchiri, ${ }^{1}$ Mostafa Ellouali, ${ }^{1}$ El Mostafa Mliji, \\ and Hassan Latrache ${ }^{1}{ }^{1}$ \\ ${ }^{1}$ Laboratory of Bioprocess and Bio-Interfaces, Faculty of Sciences and Technics, Beni Mellal, Morocco \\ ${ }^{2}$ Agro-Food Technology and Quality Laboratory, Regional Center of Agricultural Research of Tadla, \\ National Institute of Agricultural Research, Avenue Ennasr, BP 415 Rabat Principale, 10090 Rabat, Morocco \\ ${ }^{3}$ Department of Environment and Food Safety, Pasteur Institute, Casablanca, Morocco
}

Correspondence should be addressed to Kaoutar Elfazazi; ka.elfazazi@gmail.com and Hassan Latrache; latracheh@yahoo.fr

Received 7 February 2021; Revised 26 August 2021; Accepted 20 September 2021; Published 7 October 2021

Academic Editor: Karl Drlica

Copyright (c) 2021 Kaoutar Elfazazi et al. This is an open access article distributed under the Creative Commons Attribution License, which permits unrestricted use, distribution, and reproduction in any medium, provided the original work is properly cited.

\begin{abstract}
Microbial adhesion to surfaces is thought to involve physicochemical interactions between the substrate and microbial cells Understanding the physicochemical aspects involved in the adhesion phenomenon, as a critical step in biofilm formation, is essential to finding ways to prevent their formation and control biocontamination risks. The aim of this study was to investigate the relation between the adhesion behavior of 12 Escherichia coli strains isolated from food and their surface hydrophobicities using qualitative $\left(\theta_{w}\right)$ and quantitative $\left(\Delta G_{i w i}\right)$ approaches. The surface physicochemical properties of both bacterial cells and glass material were estimated through contact angle measurements. The adhesive behavior of $E$. coli strains on a glass surface was assessed. The results showed a good logarithmic relation between the percentage of the adhered cells and their surface hydrophobicity with the quantitative approach $\Delta G_{i w i}$; however, qualitative hydrophobicity $\left(\theta_{w}\right)$ appeared to demonstrate no effect regarding adhesion behavior. This work lays the foundation for future studies and opens an important debate on the mechanisms underlying the adhesion behavior of $E$. coli strains by using the thermodynamic approach $\left(\Delta G_{i w i}\right)$ as an important model of hydrophobicity that could explain and predict better bacterial adhesion ability.
\end{abstract}

\section{Introduction}

In natural environments, as well as in the food industry, microorganisms are most often attached to solid surfaces and are generally provided with sufficient nutrients to ensure their viability and growth. This adhesion ability of bacteria to surfaces is cause for concern for many industries, particularly the food industry. In fact, microbial adhesion to surfaces can act as a source of contamination, which may compromise hygienic and food quality [1]. E. coli is an important foodborne pathogen that causes thousands of cases of foodborne diseases annually across the world $[2,3]$. Several studies have been conducted, therefore, to determine the factors and mechanisms leading to the microbial attachment to food contact surfaces [4-10].

Microbial adhesion is a complex phenomenon involving several parameters and energy interactions, among which the most remarkable are the physicochemical properties of bacterial and support surfaces [4,7-14]. The interactions involved in this process are mainly Lifshitz-van der Waals, electrostatic [15], and Lewis (acid-base) ones [16]. These physicochemical interactions depend on the physicochemical properties of both the substratum and bacterial surface 
including hydrophobicity $[4,9,15,17]$ and electron donorelectron acceptor (acid-base) characteristics [10, 18].

Bacterial hydrophobicity generally refers to the tendency of a bacterial cell to interact with cells of similar hydrophobicity as opposed to water $\left(\theta_{w}\right)$ [19]. Most previous works have used the qualitative hydrophobicity $\left(\theta_{w}\right)$ measured directly by contact angle with water to explain the adhesion behavior of many bacterial species [15, 20-22]. However, several studies reported that the qualitative hydrophobicity expressed as wettability with water $\left(\theta_{w}\right)$ could not completely explain the adhesion behavior of many bacteria $[4,7,20,21,23]$. Therefore, the free energy of interaction $\left(\Delta G_{i w i}\right)$ was proposed by Van Oss et al. [24] as a quantitative method to assess cell hydrophobicity. This parameter is directly related to the interfacial tension and considers not only the contact angle measured with water $\left(\theta_{w}\right)$ but also the Lifshitz-van der Waals and acid-base interactions (electron donor and electron acceptor properties). To our knowledge, no previous work has discussed which hydrophobicity method could better explain the microbial adhesion behavior of $E$. coli strains.

To control biocontamination in food environments, it is important to understand the physicochemical aspects involved in the initial deposition of bacteria onto surfaces. Therefore, this study investigates the relation between the adhesion behavior of $12 \mathrm{E}$. coli strains isolated from food and their surface hydrophobicities using qualitative $\left(\theta_{w}\right)$ and quantitative $\left(\Delta G_{i w i}\right)$ approaches.

\section{Materials and Methods}

2.1. Bacterial Strain Selection. Twelve Escherichia coli strains isolated from food and identified at the Laboratory of Microbiology and Hygiene of Food and Environment of the Pasteur Institute Morocco were used in this study. One hundred samples received for a month from different food sources (catering, food industries, hotels, and supermarkets) were analyzed. The procedures for isolation of E. coli from different samples given in this protocol follow the ISO-93081:2014 standards [25].

Among the examined samples, 12 out of 100 samples were tested positive for $E$. coli isolation. Positive samples showed typical pink colonies on MacConkey agar and showed characteristic green metallic sheen on EMB agar. Biochemical characters showed citrate utilization test negative, H2S production in TSI agar negative, indole production positive, urease activity negative, methyl red test positive, Voges-Proskauer negative, and lysine decarboxylase positive. The isolates were confirmed also using a biochemical test (Api 20E, BioMérieux, France).

Typing of E. coli isolates was performed in the Laboratory of Microbiology and Hygiene of Food and
Environment of the Pasteur Institute Morocco according to Kauffmann and Das Kauffmann [26]. The E. coli strains were typed (13; 19; 38; 64; 76; 65; EI1; EI2; EI3; EI4; EM3; and EM4) as a function of the samples' codes and then stored at $-20^{\circ} \mathrm{C}$ in glycerol stocks before analysis.

\subsection{Bacterial Growth Conditions and Preparation of Bacterial} Suspensions. Each bacterial strain was incubated overnight at $37^{\circ} \mathrm{C}$ in Liquid Luria-Bertani (LLB) medium, which contains tryptone, yeast extract, and $\mathrm{NaCl}$. After $24 \mathrm{~h}$ of incubation, bacterial cells were harvested by centrifugation at $8400 \times \mathrm{g}$ for $15 \mathrm{~min}$, and washed twice with, and resuspended in, $\mathrm{KNO}_{3}$ solution with ionic strength $0.1 \mathrm{M}$. The bacterial optical densities (ODs) were adjusted using a spectrophotometer to approximately 0.7 and 0.8 corresponding to $10^{8} \mathrm{CFU} / \mathrm{mL}$ for subsequent experiments [9]. The bacterial suspension was filtered using a $0.45 \mu \mathrm{m}$ cellulose acetate filter (Sartorius). A thick lawn of cells was obtained after filtration by means of negative pressure. The wet filters were placed carefully on a glass support with double-sided sticky tape and allowed to air-dry until the socalled stable plateau contact angles could be measured [9].

2.3. Cleaning and Preparation of Solid Surfaces. The substrate used for the adhesion experiments was glass. The glass samples were microscope slides (RS, France). Before each experiment, substrates were immersed in 95\% ethanol for $15 \mathrm{~min}$ and then rinsed six times with distilled water. Finally, the substrate was autoclaved for $15 \mathrm{~min}$ at $120^{\circ} \mathrm{C}$ [9].

2.4. Cell Surface and Substratum Characterization. The physicochemical properties of the bacterial surface and substratum were determined using a goniometer (GBX instruments) by the sessile drop method according to Busscher [27]. The surface energy of bacteria and substratum surfaces was determined by measuring the contact angle with three liquids: water, formamide $99 \%$, and diiodomethane $99 \%$. Three to six drops of liquid were placed on each solid material and bacterial filter (described earlier).

The qualitative hydrophobicity expressed as $\theta_{w}$ was directly analyzed by measuring the contact angle with water. The quantitative hydrophobicity was determined using the Van Oss approach [24], which explains hydrophobicity as the free energy of interaction between two materials when immersed in water, denoted as $\Delta G_{i w i}$. The surface is considered hydrophobic or hydrophilic if its free energy is negative $\left(\Delta G_{i w i}<0\right)$ or positive $\left(\Delta G_{i w i}>0\right)$, respectively. The free energy can be estimated from the surface tensions of interacting entities according to the following formula:

$$
\Delta G_{i w i}=-2 \gamma_{i w}=-2\left(\left(\left(\gamma_{i}^{\mathrm{LW}}\right)^{1 / 2}-\left(\gamma_{w}^{\mathrm{LW}}\right)^{1 / 2}\right)^{2}+2\left(\left(\gamma_{i}^{+} \gamma_{i}^{-}\right)^{1 / 2}+\left(\gamma_{w}^{-} \gamma_{w}^{+}\right)^{1 / 2}-\left(\gamma_{i}^{+} \gamma_{w}^{-}\right)^{1 / 2}-\left(\gamma_{w}^{+} \gamma_{i}^{-}\right)^{1 / 2}\right)\right)
$$


Furthermore, the electron donor $\left(\gamma^{-}\right)$and acceptor $\left(\gamma^{+}\right)$ characteristics and the Lifshitz-van der Waals $\left(\gamma^{\mathrm{LW}}\right)$ interactions were estimated by the approach proposed by Van Oss [24]; the contact angle can be expressed as follows:

$$
\operatorname{Cos} \theta=\frac{-1+2\left(\gamma_{S}^{\mathrm{LW}} \gamma_{L}^{\mathrm{LW}}\right)^{1 / 2} / \gamma_{L}+2\left(\gamma_{S}^{+} \gamma_{L}^{-}\right)^{1 / 2} / \gamma_{L}+2\left(\gamma_{S}^{-} \gamma_{L}^{+}\right)^{1 / 2}}{\gamma_{L}},
$$

where $S$ and $L$ denote solid surface and liquid phases, respectively.

Lastly, the Lewis acid-base components can be identified as follows:

$$
\gamma^{A B}=2\left(\gamma_{S}^{-} \gamma_{S}^{+}\right)^{1 / 2}
$$

The surface free energy components of water, formamide, and diiodomethane are known (Table 1), but the corresponding values for the entity $i$ have to be determined.

2.5. Adhesion Assay. The bacterial suspension was placed in a Petri dish containing the sterilized materials (glass). After $3 \mathrm{~h}$ of incubation at $25^{\circ} \mathrm{C}$, nonadherent cells were eliminated by three consecutive rinses with sterile distilled water $[28,29]$. The glass samples were dried at room temperature, and then a Gram coloration was performed to assess bacterial adhesion. The adhesion on the glass surface was examined by using an optical microscope $(\times 400)$ (Olympus $\mathrm{CH} 30$ ). To estimate the percentage of the surface occupied by adherent cells, the obtained images after observation by microscopy were treated using an algorithm developed in the MATLAB software program [8].

2.6. Statistical Analysis. All physicochemical analyses and adhesion assays were conducted with three repetitions. Three to six contact angle measurements were performed on each bacterial filter and glass surface. The correlations studies were carried out between water contact angle measurement $\left(\theta_{w}\right)$, the free energy of interaction $\left(\Delta G_{i w i}\right)$, and the percentage of surface occupied by adhered cells using SPSS 20.0 software.

\section{Results}

3.1. Cell Surface and Substratum Characterization. The physicochemical characteristics of both microbial cells and material surfaces play an essential role in microbial adhesion phenomena. To control and inhibit adhesion, an understanding of the mechanisms involved in the interaction between microbial cells and substrates is required. Thereby, the physicochemical surface properties of $E$. coli strains and glass surfaces were measured by the contact angle (Table 2).

Hydrophobicity is often expressed in terms of contact angle formed by a sessile drop of water $\theta_{w}$. In the present work, we used this parameter to express the qualitative hydrophobicity of both bacterial strains and substratum. According to Vogler [30], hydrophobic surfaces exhibit water contact angle values higher than $65^{\circ}$, whereas hydrophilic surfaces gave water contact angle values lower than $65^{\circ}$.

Table 2 illustrates the bacterial physicochemical characterization by the contact angle method. Based on contact angle with the water value $\theta_{w}$, the results show that $E$. coli strains codified EI1, 38, EM3, 64, 19, EM4, and EI4 showed hydrophobic values ranging from $69.44^{\circ}$ to $99.8^{\circ}$; however, the E. coli strains 13, 76, EI3, EI2, and 65 were hydrophilic $\left(33.22-56.5^{\circ}\right)$.

Using the thermodynamic approach of Van Oss $[20,21,24]$, the absolute degree of hydrophobicity was determined with $\Delta G_{i w i}$ equations expressed in formula (equation (1)). Based on this quantitative approach, the results in Table 2 show that E. coli strains codified EM4,13, 76, EI3, EI2, 65, and EI4 were also hydrophilic $\left(\Delta G_{i w i}>0\right)$, whereas the E. coli strains EI1, 38, EM3, 64, and 19 were hydrophobic $\left(\Delta G_{i w i}<0\right)$. The free energy of interaction $\Delta G_{i w i}$ ranged from hydrophilic $\left(48.6 \mathrm{~mJ} / \mathrm{m}^{2}\right)$ to hydrophobic $\left(-70.7 \mathrm{~mJ} / \mathrm{m}^{2}\right)$ values.

Referring to the results in Table 2, it appeared that the E. coli strains 13, 76, EI3, EI2, and 65 were hydrophilic according to both qualitative and quantitative approaches. Moreover, the glass surface was qualitatively $\left(\theta_{w}=36.14^{\circ}\right)$ and quantitatively $\left(\Delta G_{i w i}=38.61 \mathrm{~mJ} / \mathrm{m}^{2}\right)$ hydrophilic.

3.2. Adhesion Tests. The adhesion ability of E. coli strains isolated from food origins on an inert surface (glass) was examined. Optical microscopic images of $E$. coli strains after $3 \mathrm{~h}$ of contact on the glass are provided in Figure 1. The percentages of the occupied surface by cells on the glass are presented in Figure 2.

As observed in Figures 1 and 2, the adhesion ability of E. coli strains on a glass support varied among strains. In fact, E. coli strains 64, 19, EM3, EM4, 13, and EI3 showed a high capacity to adhere to the glass material (percentage of adhered cells $13.5 \%, 20 \%, 33 \%, 62 \%, 25 \%$, and $11 \%$, respectively). However, E. coli strains EI1, 38, EI4, 76, EI2, and 65 did not adhere significantly to the glass substratum $(0.08 \%, 0.10 \%, 8 \%, 6 \%, 2 \%$, and $0.3 \%$, respectively). Furthermore, E. coli EM4 showed a strong adhesion capacity onto glass surface samples (62\%).

A comprehensive understanding of E. coli adhesion relies on establishing how the physicochemical properties of bacterial surfaces are involved. Therefore, we investigated the correlation between the adhesion behavior of $E$. coli strains and their surface hydrophobicities with qualitative $\left(\theta_{w}\right)$ and quantitative $\left(\Delta G_{i w i}\right)$ approaches.

Using SPSS software, we analyzed several correlation models (linear, logarithmic, and exponential) between the percentage of adhered cells of $E$. coli strains and their surface hydrophobicities with both approaches $\left(\theta_{w} ; \Delta G_{i w i}\right)$ to identify the best correlation model revealing the relationship between the adhesion capacity of our strains and their surface properties.

Correlation analysis showed no significant correlation between the cells' qualitative hydrophobicity $\left(\theta_{w}\right)$ and their adhesion intensity; however, correlation results revealed a highly significant logarithmic relation between the adhesion 
TABLE 1: Surface energy of contact angle liquids according to van Oss [21].

\begin{tabular}{lccc}
\hline Liquids & $\gamma^{1 \mathrm{w}}\left(\mathrm{mJ} / \mathrm{m}^{2}\right)$ & $\gamma^{+}\left(\mathrm{m} J / \mathrm{m}^{2}\right)$ & $\gamma^{-}\left(\mathrm{mJ} / \mathrm{m}^{2}\right)$ \\
\hline Water & 21.8 & 25.5 & 25.5 \\
Formamide & 39.0 & 2.3 & 39.6 \\
Diiodomethane & 50.8 & 0 & 0 \\
\hline
\end{tabular}

$\gamma^{\mathrm{LW}}$ : Lifshitz-van der Waals forces; $\gamma^{-}$: electron donor character; $\gamma^{+}$: electron acceptor character.

TABLE 2: Contact angles, surface tension parameters, and free energy of interaction of $E$. coli strains and glass surface.

\begin{tabular}{|c|c|c|c|c|c|c|c|}
\hline \multirow[t]{2}{*}{ Strains and substratum } & \multicolumn{3}{|c|}{ Contact angles $\left({ }^{\circ}\right)$} & \multicolumn{3}{|c|}{$\begin{array}{l}\text { Surface tension: } \\
\text { components and } \\
\text { parameters }\left(\mathrm{mJm}^{-2}\right)\end{array}$} & \multirow{2}{*}{$\begin{array}{c}\text { Free energy of interaction }\left(\mathrm{mJm}^{-2}\right) \\
\text { Hydrophobicity }\left(\Delta G_{i w i}\right)\end{array}$} \\
\hline & $\theta_{\text {water }}$ & $\theta_{\text {formamide }}$ & $\theta_{\text {diiodomethane }}$ & $\gamma^{\operatorname{lw}}$ & $\gamma^{+}$ & $\Gamma^{-}$ & \\
\hline E. coli $\mathrm{EI} 1$ & $99.80(1.23)$ & $78.28(3.2)$ & $46.12(4.02)$ & 36.31 & 0.51 & 1.40 & -70.7 \\
\hline E. coli 38 & $93.70(0.67)$ & $70.88(0.34)$ & $35.02(3.22)$ & 41.92 & 0.44 & 2.31 & -68.5 \\
\hline E. coli EM3 & $77.58(1.56)$ & $66.74(1.78)$ & $53.7(2.03)$ & 32.09 & 0.25 & 13.84 & -26.1 \\
\hline E. coli 64 & $74.03(3.23)$ & $63.35(2.89)$ & $46.85(2)$ & 35.92 & 0.13 & 15.27 & -25.0 \\
\hline E. coli 19 & $74.2(3.45)$ & $63.85(4.62)$ & $64.61(1.45)$ & 25.87 & 0.60 & 14.93 & -20.7 \\
\hline E. coli EM4 & $69.44(2.38)$ & $84.28(2.01)$ & $42.2(3.66)$ & 38.39 & 7.09 & 45.82 & 11.8 \\
\hline E. coli 13 & $54.15(1.43)$ & $53.6(1.23)$ & $45.41(0.96)$ & 36.70 & 0.04 & 35.32 & 13.4 \\
\hline E. coli 76 & $56.5(3.02)$ & $57.8(2.05)$ & $64.92(2.2)$ & 25.69 & 0.62 & 35.15 & 14.6 \\
\hline E. coli EI4 & $75.38(3.56)$ & $92.06(4.01)$ & $64.2(4.33)$ & 26.11 & 4.84 & 42.71 & 16.6 \\
\hline E. coli $\mathrm{EI} 3$ & $33.22(0.96)$ & $34.58(5.1)$ & $73.42(1.06)$ & 20.95 & 5.15 & 46.11 & 19.3 \\
\hline E. coli EI2 & $42.52(2.77)$ & $44.22(2.33)$ & $65.68(4.83)$ & 25.28 & 1.98 & 42.67 & 21.3 \\
\hline E. coli 65 & $51.43(1.43)$ & $74.38(0.89)$ & $64.98(1.36)$ & 25.66 & 1.31 & 66.91 & 48.6 \\
\hline Glass & $36.14(3.2)$ & $46.28(1.53)$ & $59.52(2.15)$ & 28.79 & 0.73 & 54.90 & 38.61 \\
\hline
\end{tabular}

Standard deviation is given in the parentheses. $\theta_{\text {water }}$ : contact angle with water/qualitative hydrophobicity; $\theta_{\text {formamide }}$ contact angle with formamide;

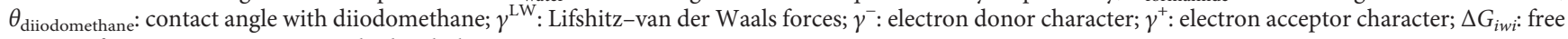
energy of interaction/quantitative hydrophobicity.

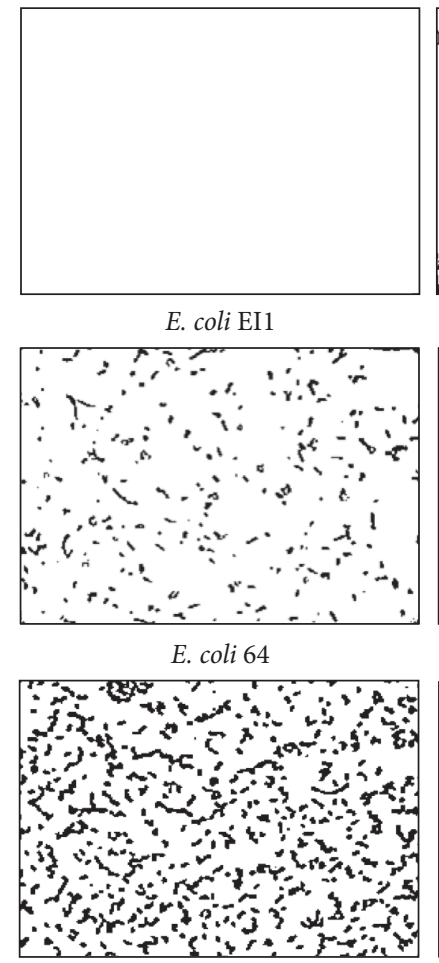

E. coli EM3

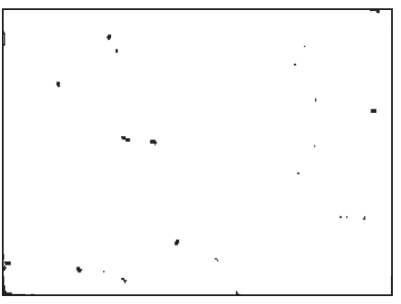

E. coli 38

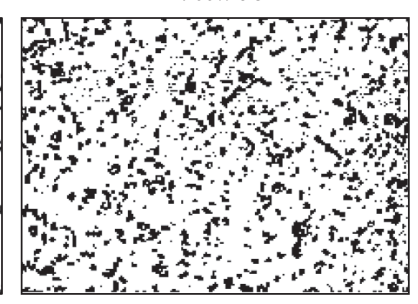

E. coli 19

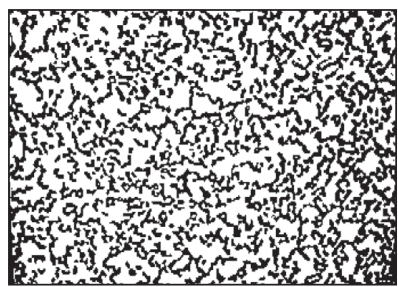

E. coli EM4

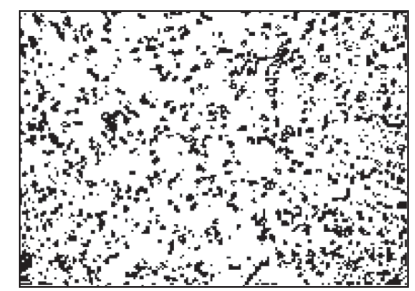

E. coli 13

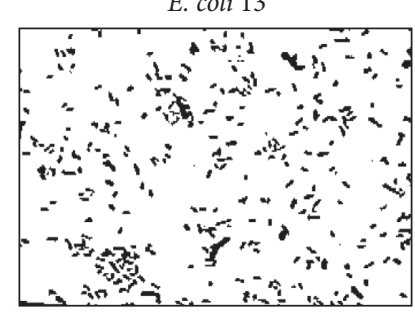

E. coli $\mathrm{E} 14$

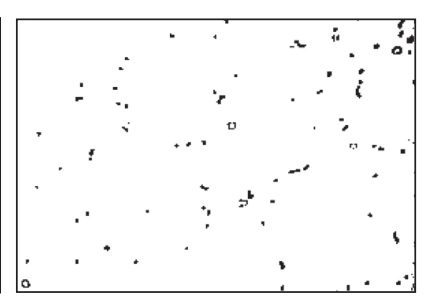

E. coli $\mathrm{E} 12$

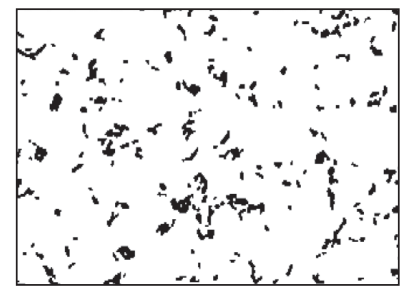

E. coli $\mathrm{E} 13$

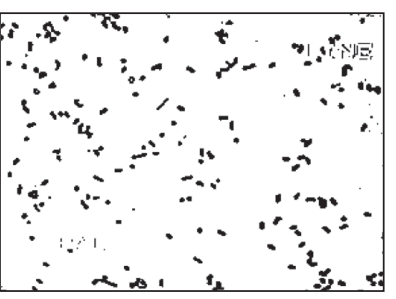

E. coli 76

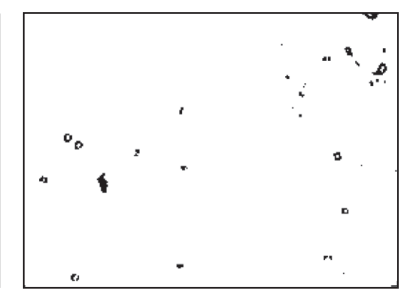

E. coli 65

FIgURE 1: Microscopic images of $E$. coli strains adhesion to glass surface at $\times 400$ magnification. Black spots are bacterial adhesion on glass surface. 


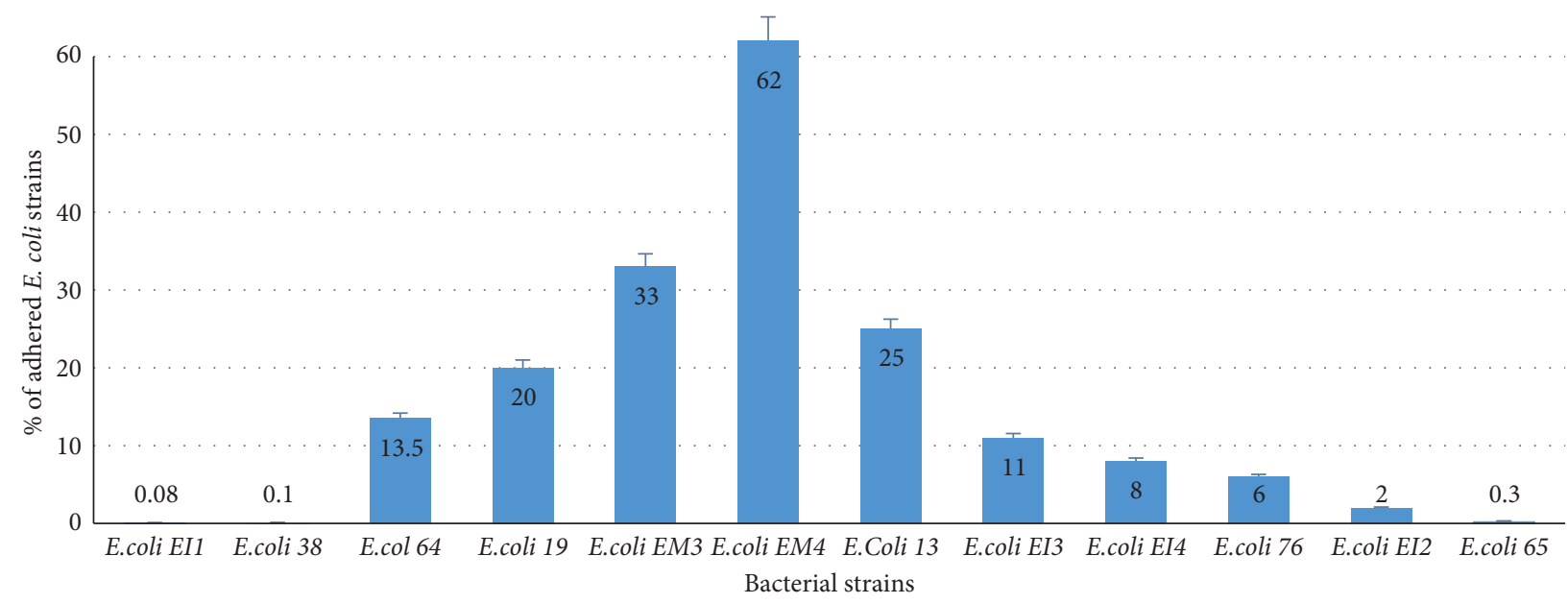

Figure 2: Percentages of the adhered cells of E. coli strains on glass substratum. Error bars represent standard deviations of the percentages of the occupied surface by bacteria. Adhesion assays were conducted with three repetitions.

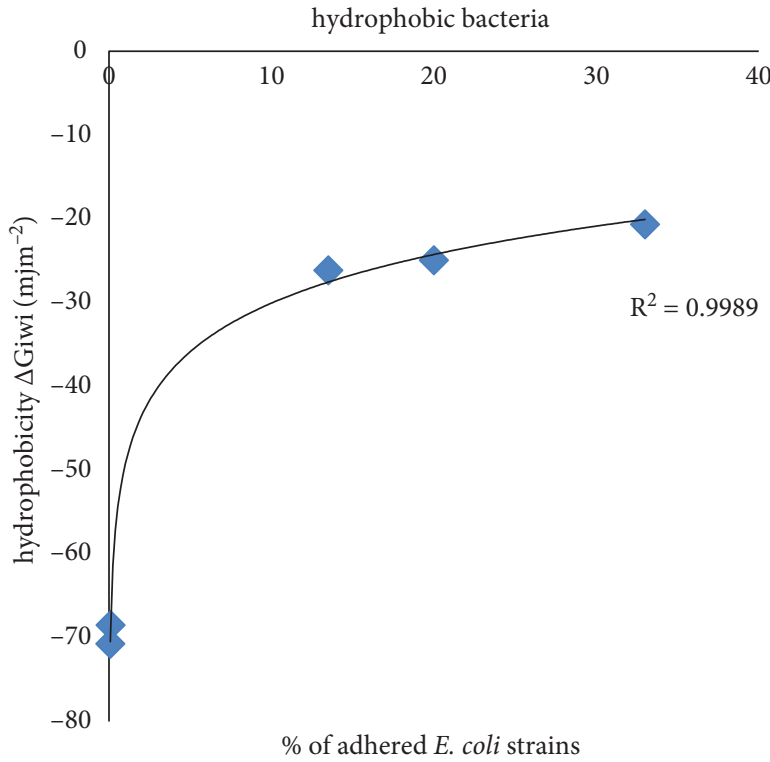

(a)

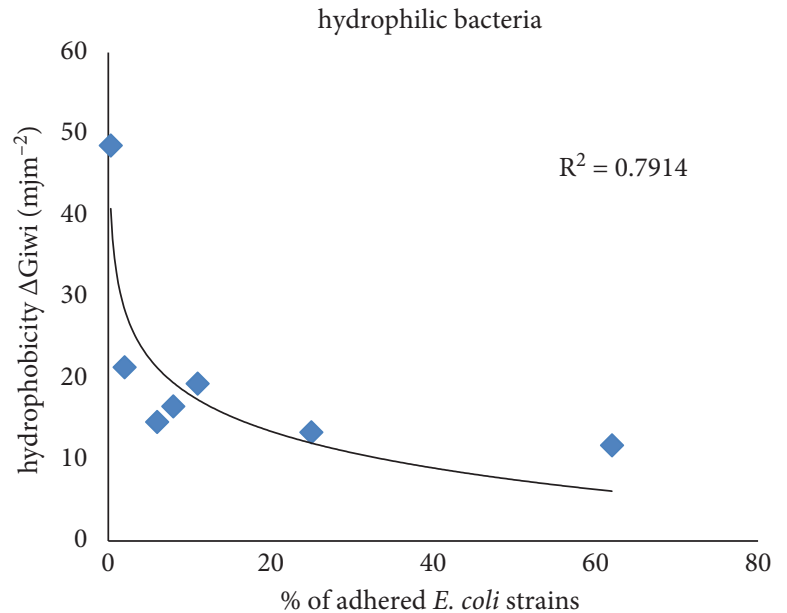

(b)

FIGURE 3: Logarithmic correlation between the bacterial surface hydrophobicity $\Delta G_{i w i}$ and the percentage of adhered cells of $E$. coli strains. (a) Hydrophobic bacteria $\Delta G_{i w i}<0$. (b) Hydrophilic bacteria $\Delta G_{i w i}>0$.

behavior of our strains and their quantitative hydrophobicity $\Delta G_{i w i}$ (Figure 3 ). The coefficient of determination $R^{2}$ indicates a good correlation between the percentage of adhered cells of $E$. coli and their surface hydrophobicity for hydrophobic $\left(R^{2}=0.9989\right)$ and hydrophilic $\left(R^{2}=0.7914\right)$ characteristics separately.

For a better understanding of this relationship between the adhesion behavior of $E$. coli strains and their hydrophobic nature, Figure 4 illustrates the distribution of the percentage of $E$. coli adhered cells as a function of their quantitative hydrophobicity $\left(\Delta G_{i w i}\right)$. The results indicated an increase and decrease in the percentage of adhered cells with negative $\left(\Delta G_{i w i}<0\right)$ and positive $\left(\Delta G_{i w i}>0\right)$ free energy of interaction values, respectively. In addition, the adhesion of E. coli strains onto the glass substrate was more pronounced when going from extreme negative and positive values of quantitative hydrophobicity $\left(\Delta G_{i w i}\right)$ to centric values (close to 0 ); however, this behavior was not observed with qualitative hydrophobicity $\left(\theta_{w}\right)$ (Figure 4 ).

\section{Discussion}

The adhesion of microorganisms to surfaces is the first step in biofilm formation. This adhesion stage is largely governed by physicochemical interactions, primarily Lifshitz-van der Waals, Lewis acid-base, and electrostatic ones. These interactions depend on the physicochemical properties that include hydrophobicity, electrostatic charge, and electron donor/electron acceptor characteristics. 


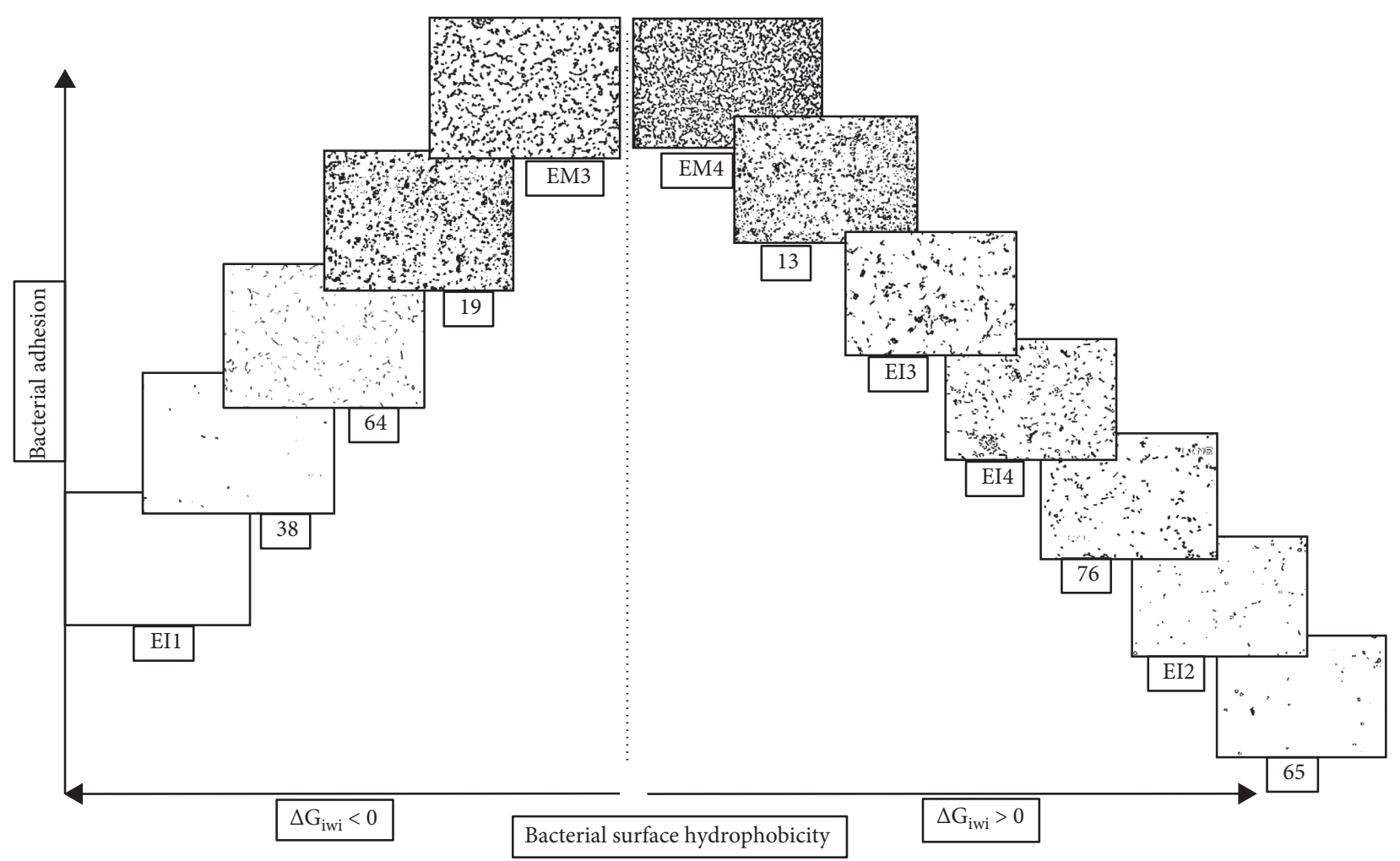

FIGURE 4: Schematic of E. coli strains adhesion behavior on glass according to their surface hydrophobicity $\left(\Delta G_{i \text { wi }}\right)$.

Surface hydrophobicity is generally thought to be the main factor in microbial adhesion. Several authors consider hydrophobicity to be the key parameter governing bacterial adhesion to surfaces $[4,15,31-36]$. Contact angle with water expressed as wettability $\left(\theta_{w}\right)$ is generally used to assess surface hydrophobicity. However, with this approach, it is only possible to evaluate hydrophobicity qualitatively $[9,10]$. Therefore, Van Oss and coworkers [24] proposed a quantitative determination of surface hydrophobicity $\Delta G_{i w i}$ that takes into account several surface properties' parameters (the electron donor $\left(\gamma^{-}\right)$and acceptor $\left(\gamma^{+}\right)$characteristics and the Lifshitz-van der Waals $\left.\left(\gamma^{\mathrm{LW}}\right)\right)$.

Several research works have used either qualitative or quantitative hydrophobicity to explain the adhesive behavior of the studied microorganisms. However, to our knowledge, no previous studies have investigated which of these hydrophobicities' parameters could explain better the adhesive behavior of $E$. coli strains. Therefore, the present study aimed to evaluate the adhesion ability of $12 \mathrm{E}$. coli strains isolated from food to adhere to an inert surface (glass) and then investigate the relation between their surface hydrophobicities and their adhesion behavior according to quantitative $\left(\Delta G_{i w i}\right)$ and qualitative $\left(\theta_{w}\right)$ approaches.

Table 2 provides the contact angle measurement results and shows that the glass support had a hydrophilic surface as determined by both qualitative $\left(\theta_{w}\right)$ and quantitative $\left(\Delta G_{i w i}\right)$ approaches, which concurs with previous researchers $[4,13,32,35,36]$. The findings in Table 2 also indicate that E. coli strains had different hydrophobicities, depending on the two aforementioned approaches. In fact, only E. coli strains $13,76, \mathrm{EI} 3, \mathrm{EI} 2$, and 65 were hydrophilic according to these approaches. These results showed similarities with those of Hamadi $[9,12]$, who reported that E. coli strains isolated from patients with urinary tract infections are hydrophilic with both approaches.

According to the literature, the hydrophobicity of a bacterial cell is largely influenced by the residues and structures on the cell surfaces, which can be hydrophilic or hydrophobic [10, 19, 37]. Hence, bacterial hydrophobicity varies among species and strains, even within the same strain, depending on the mode and stage of growth, growth medium composition, and even the analysis technique $[7,9,38,39]$, potentially explaining the variation of hydrophilicities even within the same species in our work.

The adhesion assay indicated that $E$. coli strains showed a different ability to adhere to glass materials (Figure 1). To investigate the relation between the adhesion behavior of E. coli strains and their physicochemical surface properties, we evaluated the correlation between $E$. coli adhesion behavior and their surface hydrophobicities using qualitative $\left(\theta_{w}\right)$ and quantitative $\left(\Delta G_{i w i}\right)$ strategies. The results in Figure 3 demonstrated a strong logarithmic correlation between the free energy of the interaction $\left(\Delta G_{i w i}\right)$ and the adhesion of $E$. coli strains onto glass supports; however, no significant correlation with the qualitative hydrophobicity was observed. Similarly, previous studies investigating the relationship between the hydrophobicity properties $\left(\theta_{w}\right)$ of E. coli and their attachment ability have not found a correlation between the degree of hydrophobicity of the supporting surfaces and the number of adhered cells [34, 40, 41]. 
Several works, including this one, have reported that qualitative hydrophobicity $\left(\theta_{w}\right)$ is a general concept that cannot explain systematically the microbial adhesion results for many supports [4, 42, 43]. According to Goulter [2], qualitative hydrophobicity is a general concept that cannot be directly measured but it can be only estimated by observing the bulk properties of numerous cells and interpreting these interactions as those of molecules. This could be a primary factor that makes many studies unable to find a significant correlation between qualitative hydrophobicity and adhesion behavior [4, 7, 23].

Few studies have used the thermodynamic approach in the interpretation of adhesion behavior. However, this strategy could represent an important tool in understanding microbial adhesion because it takes into account the Lifshitz-van der Waals interactions and acid-base interactions that are known to play an essential role in adhesion $[9,44]$. Based on the results obtained here, we suggest that the adhesion of $E$. coli strains on a glass substratum is mainly governed by surface quantitative hydrophobicity $\left(\Delta G_{i w i}\right)$. Therefore, we propose that the free energy of interaction $\left(\Delta G_{i w i}\right)$ should be further investigated as an important parameter to understand and predict the adhesion behavior of bacterial strains.

\section{Conclusion}

The mechanism of the initial attachment of E. coli strains to surfaces is most likely a complex process involving several factors. Many aspects, such as hydrophobicity, have been shown to play an essential role in cell attachment. This study demonstrated that qualitative hydrophobicity $\left(\theta_{w}\right)$ could not explain systematically the adhesion behavior of $12 \mathrm{E}$. coli strains; however, the quantitative hydrophobicity $\left(\Delta G_{i w i}\right)$ showed a good logarithmic relation with the percentage of adhered cells. This work provides an important approach for understanding the mechanisms underlying different aspects of adhesion behavior by focusing on studying the thermodynamic approach $\left(\Delta G_{i w i}\right)$ as an important model of hydrophobicity that could predict E. coli adhesion behavior.

To end, a comparison of $E$. coli strains adhesion on other substrates and the study of their biofilm formation could better inform on their behavior according to their surface qualitative and quantitative hydrophobicities. This strategy could help in understanding and controlling the adhesive behavior of these strains in order to reduce biocontamination risks in food industries

\section{Disclosure}

This work was part of the Research Project, RS/2011/32: "Study of Biofilm Formation on Materials Used in Food Industry." The project was part of the "Programme National du Developpement de la Recherche Sectorielle" launched by the National Centre for Scientific and Technical Research (CNRST) in collaboration with the Faculty of Science and Technology of Beni Mellal, Faculty of Science and Technology of Fez and Institute Pasteur, Morocco.

\section{Data Availability}

The data used to support the findings of this study are included within the article.

\section{Conflicts of Interest}

The authors declare that there are no conflicts of interest.

\section{Authors' Contributions}

Hassan Latrache, Hafida Zahir, and Ellouali Mostafa designed the study and corrected the final manuscript. Elfazazi Kaoutar, Btissam Mayoussi, Safae Tankiouine, and Chorouk Zanane conducted the experimental work. Souad Lekchiri contributed to data analysis and article writing and correction. El Mostafa Mliji conducted the bacterial identification. Elfazazi Kaoutar performed the data analysis and wrote the article.

\section{Acknowledgments}

The authors would like to express their most sincere gratitude to Dr. Haytham M. Hawash, researcher in microbiology and food safety at the Animal Health Research Institute of Egypt, Reference Laboratory for Veterinary Quality Control, for his invaluable assistance in reviewing this paper.

\section{References}

[1] K. Azelmad, F. Hamadi, R. Mimouni et al., "Adhesion of Staphylococcus aureus and Staphylococcus xylosus to materials commonly found in catering and domestic kitchens," Food Control, vol. 73, pp. 156-163, 2017.

[2] R. M. Goulter, I. R. Gentle, and G. A. Dykes, "Issues in determining factors influencing bacterial attachment: a review using the attachment of Escherichia coli to abiotic surfaces as an example," Letters in Applied Microbiology, vol. 49, no. 1, pp. 1-7, 2009.

[3] P. M. Griffin and R. V. Tauxe, "The epidemiology of infections caused by Escherichia coli O157: H7, other enterohemorrhagic E. coli, and the associated hemolytic uremic syndrome," Epidemiologic Reviews, vol. 13, no. 1, pp. 60-98, 1991.

[4] K. Elfazazi, "Effet des protocoles de désinfection sur les propriétés des surfaces des matériaux utilisés en industries agro-alimentaires et conséquences sur leurs biocontaminations par les Escherichia coli et les salmonelles pathogènes," Doctoral dissertation, Universitè Sultan Moulay Slimane, Faculté of science and Technics, Beni Mellal, Morocco, 2019.

[5] K. Elfazazi, H. Zahir, S. Tankiouine, C. Zanane, M. Ellouali, and H. Latrache, "Microbial adhesion of Salmonella muenster, Salmonella kentucky, Salmonella newport and Salmonella kiel: effect of ionic strength on physicochemical surface properties," Annual Research \& Review in Biology, vol. 27, no. 3, pp. 1-10, 2018.

[6] H. Zahir, H. Fatima, L. Souad, M. E. Mostafa, E. Mostafa, and L. Hassan, "Role of cell surface structures in biofilm formation by Escherichia coli," Food and Nutrition Sciences, vol. 6, no. 12, pp. 1160-1165, 2015. 
[7] H. Latrache, G. A. El, M. Karroua et al., "Relations between hydrophobicity tested by three methods and surface chemical composition of Escherichia coli," The New Microbiologica, vol. 25, no. 1, pp. 75-82, 2002.

[8] F. Hamadi, H. Latrache, M. Mabrrouki et al., "Effect of $\mathrm{pH}$ on distribution and adhesion of Staphylococcus aureus to glass," Journal of Adhesion Science and Technology, vol. 19, no. 1, pp. 73-85, 2005.

[9] F. Hamadi and H. Latrache, "Comparison of contact angle measurement and microbial adhesion to solvents for assaying electron donor-electron acceptor (acid-base) properties of bacterial surface," Colloids and Surfaces B: Biointerfaces, vol. 65, no. 1, pp. 134-139, 2008.

[10] F. Hamadi, H. Latrache, H. Zahir, A. Elghmari, M. Timinouni, and M. Ellouali, "The relation between Escherichia coli surface functional groups' composition and their physicochemical properties," Brazilian Journal of Microbiology, vol. 39, no. 1, pp. 10-15, 2008.

[11] M. Elgoulli, O. Aitlahbib, S. Tankiouine et al., "The theoretical adhesion of Pseudomonas aeruginosa and Escherichia coli on some plumbing materials in presence of distilled water or tap water," Folia Microbiologica, vol. 66, pp. 1-7, 2021.

[12] F. Hamadi, H. Latrache, H. Zahir, S. E. Abed, M. Ellouali, and I. K. Saad, "The relation between the surface chemical composition of Escherichia coli and their electron donor/ electron acceptor (acid-base) properties," Research Journal of Microbiology, vol. 7, no. 1, pp. 32-40, 2012.

[13] F. Hamadi, F. Asserne, S. Elabed, S. Bensouda, M. Mabrouki, and H. Latrache, "Adhesion of Staphylococcus aureus on stainless steel treated with three types of milk," Food Control, vol. 38, pp. 104-108, 2014.

[14] H. Latrache, N. Mozes, C. Pelletier, and P. Bourlioux, "Chemical and physicochemical properties of Escherichia coli: variations among three strains and influence of culture conditions," Colloids and Surfaces B: Biointerfaces, vol. 2, no. 1-3, pp. 47-56, 1994.

[15] M. C. van Loosdrecht, J. Lyklema, W. Norde, G. Schraa, and A. J. Zehnder, "The role of cell wall hydrophobicity in adhesion," Applied and Environmental Microbiology, vol. 53, no. 8, pp. 1893-1897, 1987.

[16] A. Vernhet and M. N. Bellon-Fontaine, "Role of bentonites in the prevention of Saccharomyces cerevisiae adhesion to solid surfaces," Colloids and Surfaces B: Biointerfaces, vol. 3, no. 5, pp. 255-262, 1995.

[17] J. T. Gannon, V. B. Manilal, and M. Alexander, "Relationship between cell surface properties and transport of bacteria through soil," Applied and Environmental Microbiology, vol. 57, no. 1, pp. 190-193, 1991.

[18] C. J. van Oss, "Acid-base interfacial interactions in aqueous media," Colloids and Surfaces A: Physicochemical and Engineering Aspects, vol. 78, pp. 1-49, 1993.

[19] H. C. van der Mei, M. M. Cowan, and H. J. Busscher, "Physicochemical and structural studies on Acinetobacter calcoaceticus RAG-1 and MR-481-two standard strains in hydrophobicity tests," Current Microbiology, vol. 23, no. 6, pp. 337-341, 1991.

[20] C. J. van Oss, "Hydrophobicity of biosurfaces-origin, quantitative determination and interaction energies," Colloids and Surfaces B: Biointerfaces, vol. 5, no. 3-4, pp. 91-110, 1995.

[21] C. J. van Oss, "Hydrophobicity and hydrophilicity of biosurfaces," Current Opinion in Colloid \& Interface Science, vol. 2, no. 5, pp. 503-512, 1997.

[22] H. J. Busscher, B. van de Belt-Gritter, and H. C. van der Mei, "Implications of microbial adhesion to hydrocarbons for evaluating cell surface hydrophobicity 1 . zeta potentials of hydrocarbon droplets," Colloids and Surfaces B: Biointerfaces, vol. 5, no. 3-4, pp. 111-116, 1995.

[23] L. Rivas, N. Fegan, and G. A. Dykes, "Physicochemical properties of shiga toxigenic Escherichia coli," Journal of Applied Microbiology, vol. 99, no. 4, pp. 716-727, 2005.

[24] C. J. van Oss, R. J. Good, and M. K. Chaudhury, "Additive and nonadditive surface tension components and the interpretation of contact angles," Langmuir, vol. 4, no. 4, pp. 884-891, 1988.

[25] C. R. Fricker, S. Bullock, K. Murrin, and S. I. Niemela, "Use of the ISO 9308-1 procedure for the detection of E. coli in water utilizing two incubation temperatures and two confirmation procedures and comparison with defined substrate technology," Journal of Water and Health, vol. 6, no. 3, pp. 389-397, 2008.

[26] F. Kauffmann and W. Das-Kauffmann, Antigenic Formulas of the Salmonella Serovars, WHO Co-Operating Centre for Reference and Research on Salmonella, Paris, France, 8th edition, 2001.

[27] H. J. Busscher, A. H. Weerkamp, H. C. van der Mei, A. W. van Pelt, H. P. de Jong, and J. Arends, "Measurement of the surface free energy of bacterial cell surfaces and its relevance for adhesion," Applied and Environmental Microbiology, vol. 48, no. 5, pp. 980-983, 1984.

[28] P. J. Herald and E. A. Zottola, "Scanning electron microscopic examination of Yersinia enterocolitica attached to stainless steel at selected temperatures and $\mathrm{pH}$ values," Journal of Food Protection, vol. 51, no. 6, pp. 445-448, 1988.

[29] R. Briandet, T. Meylheuc, C. Maher, and M. N. BellonFontaine, "Listeria monocytogenes scott a: cell surface charge, hydrophobicity, and electron donor and acceptor characteristics under different environmental growth conditions," Applied and Environmental Microbiology, vol. 65, no. 12, pp. 5328-5333, 1999.

[30] E. A. Vogler, "Structure and reactivity of water at biomaterial surfaces," Advances in Colloid and Interface Science, vol. 74, no. 1-3, pp. 69-117, 1998.

[31] S. Cappello and S. P. P. Guglielmino, "Effects of growth temperature on polystyrene adhesion of Pseudomonas aeruginosa ATCC 27853," Brazilian Journal of Microbiology, vol. 37, no. 3, pp. 205-207, 2006.

[32] T. K. Jana, A. K. Srivastava, K. Csery, and D. K. Arora, "Influence of growth and environmental conditions on cell surface hydrophobicity of Pseudomonas fluorescens in nonspecific adhesion," Canadian Journal of Microbiology, vol. 46, no. 1, pp. 28-37, 1999.

[33] R. Pereira, D. Cavalcanti, and V. Teixeira, "Effects of secondary metabolites from the tropical brazilian brown alga dictyota menstrualis on the amphipod Parhyale hawaiensis," Marine Ecology Progress Series, vol. 205, pp. 95-100, 2000.

[34] R. Oliveira, J. Azeredo, P. Teixeira, and A. P. Fonseca, "The role of hydrophobicity in bacterial adhesion," in Biofilm Community Interactions: Chance or Necessity? Cardiff, P. Gilbert, D. Allison, M. Brading, J. Verran, and J. Walker, Eds., pp. 11-22, Bioline, UK, 2001.

[35] S. K. Hood and E. A. Zottola, "Adherence to stainless steel by foodborne microorganisms during growth in model food systems," International Journal of Food Microbiology, vol. 37, no. 2-3, pp. 145-153, 1997.

[36] K. W. Millsap, G. Reid, H. C. Van der Mei, and H. J. Busscher, "Adhesion of Lactobacillus species in urine and phosphate buffer to silicone rubber and glass under flow," Biomaterials, vol. 18, no. 1, pp. 87-91, 1997. 
[37] M. Elgoulli, S. Tankiouine, O. Aitlahbib, H. Zahir, M. El Louali, and H. Latrache, "Effect of water temperature on surfaces' physicochemical properties and adhesion of Pseudomonas aeruginosa in turbulence conditions," Eurasian Journal of Biosciences, vol. 14, no. 2, pp. 7245-7251, 2020.

[38] A. Assaidi, M. Ellouali, H. Latrache et al., "Adhesion of Legionella pneumophila on glass and plumbing materials commonly used in domestic water systems," International Journal of Environmental Health Research, vol. 28, no. 2, pp. 125-133, 2018.

[39] H. Latrache, "Les propriétés de la surface d'Escherichia coli uropathogène et leur variation aprés culture en présence de concentrations subinhibitrices de nitroxoline," Doctoral dissertation, Paris, France, 1993.

[40] J. Li and L. A. McLandsborough, "The effects of the surface charge and hydrophobicity of Escherichia coli on its adhesion to beef muscle," International Journal of Food Microbiology, vol. 53, no. 2-3, pp. 185-193, 1999.

[41] A. N. Hassan and J. F. Frank, "Attachment of Escherichia coli O157: H7 grown in tryptic soy broth and nutrient broth to apple and lettuce surfaces as related to cell hydrophobicity, surface charge, and capsule production," International Journal of Food Microbiology, vol. 96, no. 1, pp. 103-109, 2004.

[42] S. McEldowney and M. Fletcher, "Variability of the influence of physicochemical factors affecting bacterial adhesion to polystyrene substrata," Applied and Environmental Microbiology, vol. 52, no. 3, pp. 460-465, 1986.

[43] J. Sjollema, H. C. van der Mei, H. M. W. Uyen, and H. J. Busscher, "The influence of collector and bacterial cell surface properties on the deposition of oral streptococci in a parallel plate flow cell," Journal of Adhesion Science and Technology, vol. 4, no. 1, pp. 765-777, 1990.

[44] M. Henriques, J. Azeredo, and R. Oliveira, "Adhesion of Candida albicans and Candida dubliniensis to acrylic and hydroxyapatite," Colloids and Surfaces B: Biointerfaces, vol. 33, no. 3-4, pp. 235-241, 2004. 